\title{
Lubricating Properties of Cyano-Based Ionic Liquids against Tetrahedral Amorphous Carbon Film
}

\author{
Shouhei Kawada ${ }^{1, *}$ (D) Hikaru Okubo ${ }^{1}$, Seiya Watanabe ${ }^{1}$, Chiharu Tadokoro ${ }^{2}$, Ryo Tsuboi ${ }^{3}$, \\ Shinya Sasaki ${ }^{1}$ and Masaaki Miyatake ${ }^{1}$ \\ 1 Department of Mechanical Engineering, Tokyo University of Science, 6-3-1 Niijyuku, Katsushika-ku, \\ Tokyo 125-8585, Japan; 4516701@alumni.tus.ac.jp (H.O.); s-watanabe@rs.tus.ac.jp (S.W.); \\ s.sasaki@rs.tus.ac.jp (S.S.); m-miyatake@rs.tus.ac.jp (M.M.) \\ 2 Department of Mechanical Engineering, Saitama University, 255 Shimo-Okubo, Sakura-ku, Saitama-shi, \\ Saitama 338-8570, Japan; tadokoro@mail.saitama-u.ac.jp \\ 3 Department of Mechanical Engineering, Daido University, 10-3 Takiharu-cho, Minami-ku, Nagoya-shi, \\ Aichi 457-8530, Japan; r-tsuboi@daido-it.ac.jp \\ * Correspondence: s-kawada@rs.tus.ac.jp
}

Received: 31 December 2019; Accepted: 7 February 2020; Published: 8 February 2020

\begin{abstract}
Ionic liquids have unique characteristics, which render them ideal candidates as new base oils or additives. In particular, there are great expectations from the combination of diamond-like carbon and cyano-based ionic liquids. Lubricating properties of cyano-based ionic liquids have been studied on specific tetrahedral amorphous carbon (ta-C) films. After lubrication, ta-C film/ta-C film contact interface exhibits exceedingly low friction. Therefore, it is necessary to understand this low friction phenomenon. The current study evaluated the lubricating mechanism of cyano-based ionic liquids against ta-C films. 1-Butyl-3-methylimidazolium dicyanamide ((BMIM)(DCN)) and 1-butyl-3-methylimidazolium tricyanomethane ((BMIM)(TCC)) were used as lubricants, with the latter exhibiting low friction coefficient of 0.03 . Steel cylinders and disks with ta-C films were used as test specimens. Raman spectroscopy, matrix-assisted laser desorption/ionization time-of-flight mass spectrometry, and thermogravimetric analysis (TGA) helped us understand the mechanism of low friction induced by (BMIM)(TCC). Graphitization of the ta-C film at high temperatures might have caused the reduction in friction between the films. Similarly, anion adsorption on the worn surface at high temperatures also led to reduced friction. However, the TGA result showed a different trend than that of the sliding test. Our results indicate that the cyano-based ionic liquids underwent tribo-decomposition at low temperatures. Further, a minimum temperature was required for the adsorption of anions onto the sliding surface.
\end{abstract}

Keywords: friction reduction; ionic liquid; lubrication; surface chemistry; tetrahedral amorphous carbon

\section{Introduction}

"Ionic crystal" is a solid-state material consisting of cations and anions, such as sodium chloride, sodium acetate, and ammonium chloride. Despite being a salt, ionic liquids exist in the liquid phase at a temperature of $100{ }^{\circ} \mathrm{C}$ or lower [1-3]. They are good candidates as new lubricant oils or additives because of their unique characteristics, including their non-volatility, low vapor pressure, the ability to remain in the liquid phase over a wide temperature range, low viscosity, and an infinite number of ion combinations [4-8]. Kondo et al. reported the use of ionic liquids as adsorption films for magnetic thin films inspired by the use of ionic liquids in the tribology field [9-11]. Ionic liquids that include elemental fluorine exhibit low friction at steel/steel contacts due to the generation of ferrous fluoride. However, severe corrosion occurs on the worn surface, and hazardous hydrogen fluorine is 
produced through reaction with moisture [12-14]. This corrosion can be prevented with the use of ionic liquids under inert atmosphere, but the corrosion may occur after the atmospheric relief [15]. From the viewpoint of environmental conservation, the usage of halogen-free ionic liquids is desirable. There are various types of halogen-free ionic liquids. The sulfate- and phosphate-based ionic liquids form reaction films on the worn surface at steel/steel contacts, thereby leading to low friction coefficient or small wear volume [16]. The cyano-based ionic liquids exhibit low friction via the formation of an adsorption film of their anions [17-20]. Boron-based ionic liquids also exhibit low friction; however, the detailed mechanism is still not clear [21]. Further, various cations are also being investigated, which include phosphonium and ammonium cations. They increase the solubility of the ionic liquids in the base oils and make it possible to study them as lubricant additives [22-25]. In addition, very low friction caused by the ionic liquids has been reported in recent years. One of the applications is their use as a swelling agent for polymer brushes [26-28]. These polymer brushes exhibit an ultra-low friction coefficient of less than $0.01[27,28]$. Diamond-like carbon (DLC) is also used as one of the effective friction materials for reducing friction between surfaces [29,30]. Lubricating properties of cyano-based ionic liquids in steel/DLC and DLC/DLC contacts have been evaluated, and these combinations have been reported to exhibit low friction [17,20,31-33]. Further, AISI52100/tetrahedral amorphous carbon (ta-C) film and ta-C film/ta-C film contacts exhibited very low friction of 0.02 and 0.018 , respectively. The combination of a cyano-based ionic liquid and ta-C film has the potential to be a novel lubrication system. However, a detailed lubricating mechanism for this combination is poorly understood.

In this study, the lubricating properties of cyano-based ionic liquids against a ta-C film were evaluated using a reciprocating sliding friction and wear tester. We focused on the conditions at which low friction was observed and the relationship of the molecular structures of cyano-based ionic liquids and ta-C film. Two types of cyano-based ionic liquids, 1-butyl-3-methylimidazolium dicyanamide (BMIM)(DCN) and 1-butyl-3-methylimidazolium tricyanomethane (BMIM)(TCC), were used as lubricants. In order to clarify the reason for the low friction, various investigations were made using techniques including thermogravimetric analysis (TGA), Raman spectroscopy, and matrix-assisted laser desorption/ionization time-of-flight mass spectrometry (MALDI-TOF/MS).

\section{Materials and Methods}

\subsection{Lubricants and Materials}

In this study, (BMIM)(DCN) and (BMIM)(TCC) purchased from Merck (Darmstadt, Germany) were used as lubricants. The molecular structures and physical properties of these ionic liquids are listed in Tables 1 and 2, respectively. Their viscosities were measured with a tuning fork vibration viscometer (SV-1A, A\&D Company, Tokyo, Japan). Their purity and melting points were catalog values.

Table 1. Molecular structures of cyano-based ionic liquids. 1-Butyl-3-methylimidazolium dicyanamide ((BMIM)(DCN)); 1-butyl-3-methylimidazolium tricyanomethane ((BMIM)(TCC)).
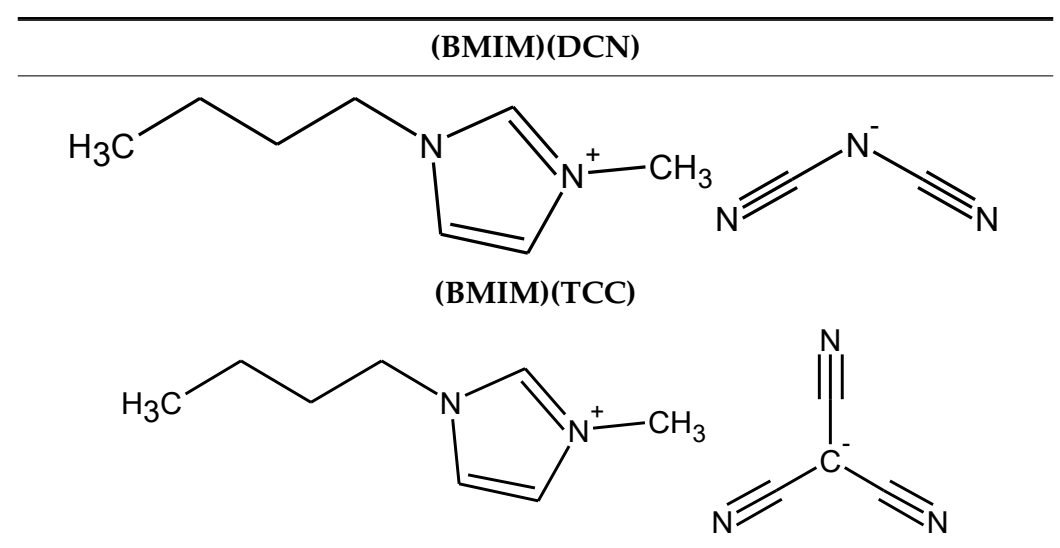
Table 2. Physical properties of the ionic liquids.

\begin{tabular}{ccc}
\hline Name & (BMIM)(DCN) & (BMIM)(TCC) \\
\hline Viscosity $\left(50{ }^{\circ} \mathrm{C}\right)$ & $11.6[\mathrm{mPas}]$ & $11.1[\mathrm{mPas}]$ \\
Melting point & $<-50\left[{ }^{\circ} \mathrm{C}\right]$ & $<-50\left[{ }^{\circ} \mathrm{C}\right]$ \\
Purity & $>98[\%]$ & $>98[\%]$ \\
\hline
\end{tabular}

AISI 52,100 steel cylinders (diameter: $15 \mathrm{~mm}$; length: $22 \mathrm{~mm}$; HRC60) and AISI 52100 steel disks (diameter: $24 \mathrm{~mm}$; thickness: $7.9 \mathrm{~mm}$; HRC60) with a ta-C film coating were used as sliding materials. The cylinders and disks were procured from Test Materials (Tokyo, Japan). The ta-C film-coated steel disks were produced by the ITF Co. (Kyoto, Japan) by arc ion plating. Table 3 lists the properties of the ta-C film. The hardness of this film was measured with a tribo-indenter (Ti950, Hysitron, Minneapolis, MN, USA), and the coating thickness was measured with a coating thickness analyzer (Calotest, Anton Paar Tritec SA, Neuchâtel, Switzerland).

Table 3. Physical properties of the ta-C film.

\begin{tabular}{cc}
\hline Roughness & $\boldsymbol{R}_{\mathrm{a}}=\mathbf{0 . 0 1}[\mu \mathrm{m}]$ \\
\hline Hardness & $73[\mathrm{GPa}]$ \\
Film thickness & $1.0[\mu \mathrm{m}]$ \\
Hydrogen content & $<1.0[\mathrm{at} \%]$ \\
Interlayer & $\mathrm{Cr}$ \\
\hline
\end{tabular}

\subsection{Sliding Tests}

The lubricating properties were evaluated with a reciprocating sliding tester (SRV4, Optimol, Langenbach, Germany). Before testing, the specimens were ultrasonically cleaned with a mixed solution of petroleum benzine and acetone at 1:1 ratio for $10 \mathrm{~min}$. Then, $90 \mu \mathrm{L}$ of the ionic liquid was applied to the disk surface. The operating parameters for the sliding tests were as follows: temperature of $30-290{ }^{\circ} \mathrm{C}$, programmed heating rate of $10 \mathrm{~K}$ per $5 \mathrm{~min}$, air atmosphere, load of $50 \mathrm{~N}$, reciprocating frequency of $50 \mathrm{~Hz}$, and amplitude of $1 \mathrm{~mm}$. The sliding test was stopped when a sharp increase in the friction coefficient was reached. Constant temperature sliding tests were conducted at approximately $30^{\circ} \mathrm{C}$, and the temperature at which a low friction coefficient was achieved was determined to study the mechanism of low friction. The operating parameters were as follows: load of $50 \mathrm{~N}$, sliding time of $30 \mathrm{~min}$, reciprocating frequency of $50 \mathrm{~Hz}$, and amplitude of $1 \mathrm{~mm}$. This sliding test was stopped when the friction reduction effect was observed. The tests were confirmed to be reproducible. After the sliding tests, the disk specimens were ultrasonically cleaned with a mixed solution of petroleum benzine and acetone for $10 \mathrm{~min}$. The surface images of the disk specimens after the sliding tests were obtained using a laser microscope (VK-X150, Keyence, Osaka, Japan). Each surface profile was obtained by a surface profile meter (SURFCOM 1500SD3, ACCRETECH, Tokyo, Japan), with respect to the vertical direction of the wear track. 


\subsection{Raman Spectroscopy}

The structural changes in the wear track of ta-C films were investigated by Raman spectroscopy (inVia Raman Microscope, Renishaw, Gloucestershire, UK). The Raman spectrometer used a $532 \mathrm{~nm}$ YAG laser with a maximum output power of $2.5 \mathrm{~mW}$ in conjunction with an objective lens at $50 \mathrm{x}$ magnification. The Raman spectra of the amorphous carbon showed some prominent features (D-peak at approximately $1300-1400 \mathrm{~cm}^{-1}$ and G-peak at $1500-1600 \mathrm{~cm}^{-1}$ ) [34]. The increase in the ratio of the D-peak to G-peak intensities $\left(I_{\mathrm{D}} / I_{\mathrm{G}}\right)$ indicates the degree of graphitization of the ta-C film [35]. Graphitization (increase in $I_{\mathrm{D}} / I_{\mathrm{G}}$ ) of the film is known to influence the friction behavior [36]. In this study, the degree of graphitization was estimated by calculating the $I_{\mathrm{D}} / I_{\mathrm{G}}$ ratio.

\subsection{MALDI-TOF/MS Analysis}

The surface information for the worn surface of each disk was obtained by MALDI-TOF/MS analysis (autoflex speed, Bruker, Billerica, MA, USA). The wavelength of the laser was $337 \mathrm{~nm}$, acceleration voltage was $20 \mathrm{kV}$, and step size was $100 \mu \mathrm{m}$. The measurement area was approximately $9 \mathrm{~mm}^{2}\left(3 \times 3 \mathrm{~mm}^{2}\right)$. The reflected mode was used for the analysis, and the laser beam diameter was $100 \mu \mathrm{m}$. The measured mass range was 1-3000 m/e. Before analysis, the sample surface was ultrasonically cleaned with a solution of petroleum benzine and acetone for $10 \mathrm{~min}$.

\subsection{Thermogravimetric Analysis}

The thermal stability of the used ionic liquids was evaluated by TGA (TG-DTA2010SA, Bruker, Billerica, MA, USA). TGA of the samples was carried out in aluminum pans in nitrogen atmosphere in a temperature range of $30-500{ }^{\circ} \mathrm{C}$ at a programmed heating rate of $10 \mathrm{~K} / \mathrm{min}$.

\section{Results}

\subsection{Friction Tests}

Figure 1 shows the frictional behavior of each cyano-based ionic liquid at an elevated temperature. In the case of (BMIM)(DCN), the friction coefficient gradually increased with the temperature. A reduction in friction was observed at $170^{\circ} \mathrm{C}$. The friction coefficient was approximately 0.07 . After this, a sharp increase in the friction coefficient was observed at $210^{\circ} \mathrm{C}$, because the ta-C film might have peeled from the substrate. When (BMIM)(TCC) was used, the friction coefficient gradually increased with the temperature. At $90{ }^{\circ} \mathrm{C}$, the friction coefficient decreased to approximately 0.03. A sharp increase in the friction coefficient was then observed at $110^{\circ} \mathrm{C}$, which confirmed that the temperature affected the reactivity of the ionic liquids. We performed the sliding test at a constant temperature and confirmed the time-dependence of the friction coefficient to clarify the effect of temperature. Figure 2 shows the frictional behavior of the ionic liquids at $30^{\circ} \mathrm{C}$, and the temperature at which a low friction coefficient was achieved. To determine the temperature corresponding to the low friction coefficient of the ionic liquids, friction tests were conducted at $170{ }^{\circ} \mathrm{C}$ and $100{ }^{\circ} \mathrm{C}$ for (BMIM)(DCN) and (BMIM)(TCC), respectively. Figure 3 shows an image of the worn surface of the ta-C film obtained with a laser microscope. Figures 4 and 5 show the worn surface profiles of the ta-C film lubricated with each ionic liquid. At $30^{\circ} \mathrm{C}$, both ionic liquids showed stable friction behaviors and small surface wear. At the temperature corresponding to the low friction coefficient, the reduced friction of each ionic liquid was confirmed. Further, the progression of wear was confirmed in comparison with the results obtained at $30^{\circ} \mathrm{C}$. 


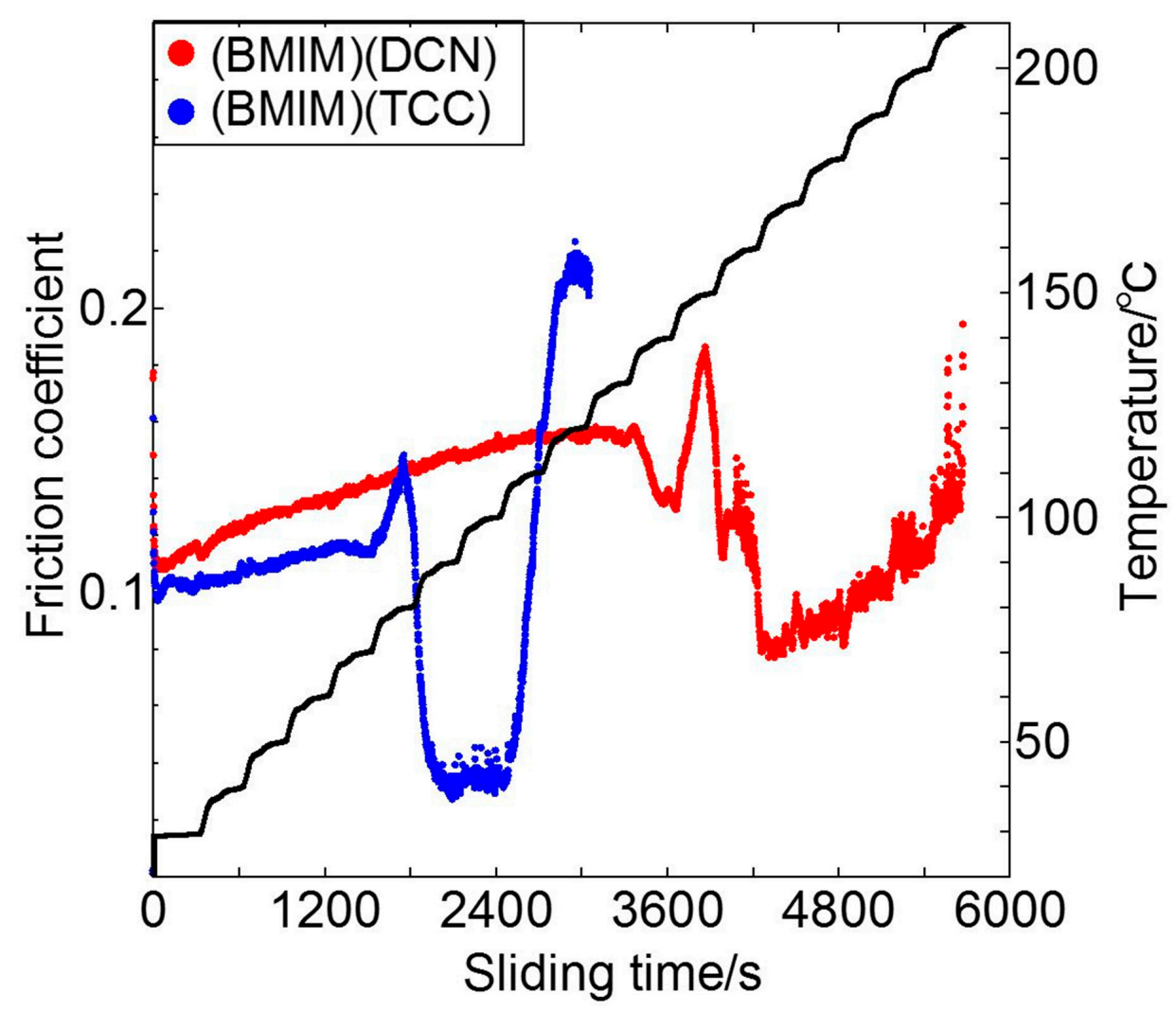

Figure 1. Friction behaviors of (BMIM)(DCN) and (BMIM)(TCC) at elevated temperatures.

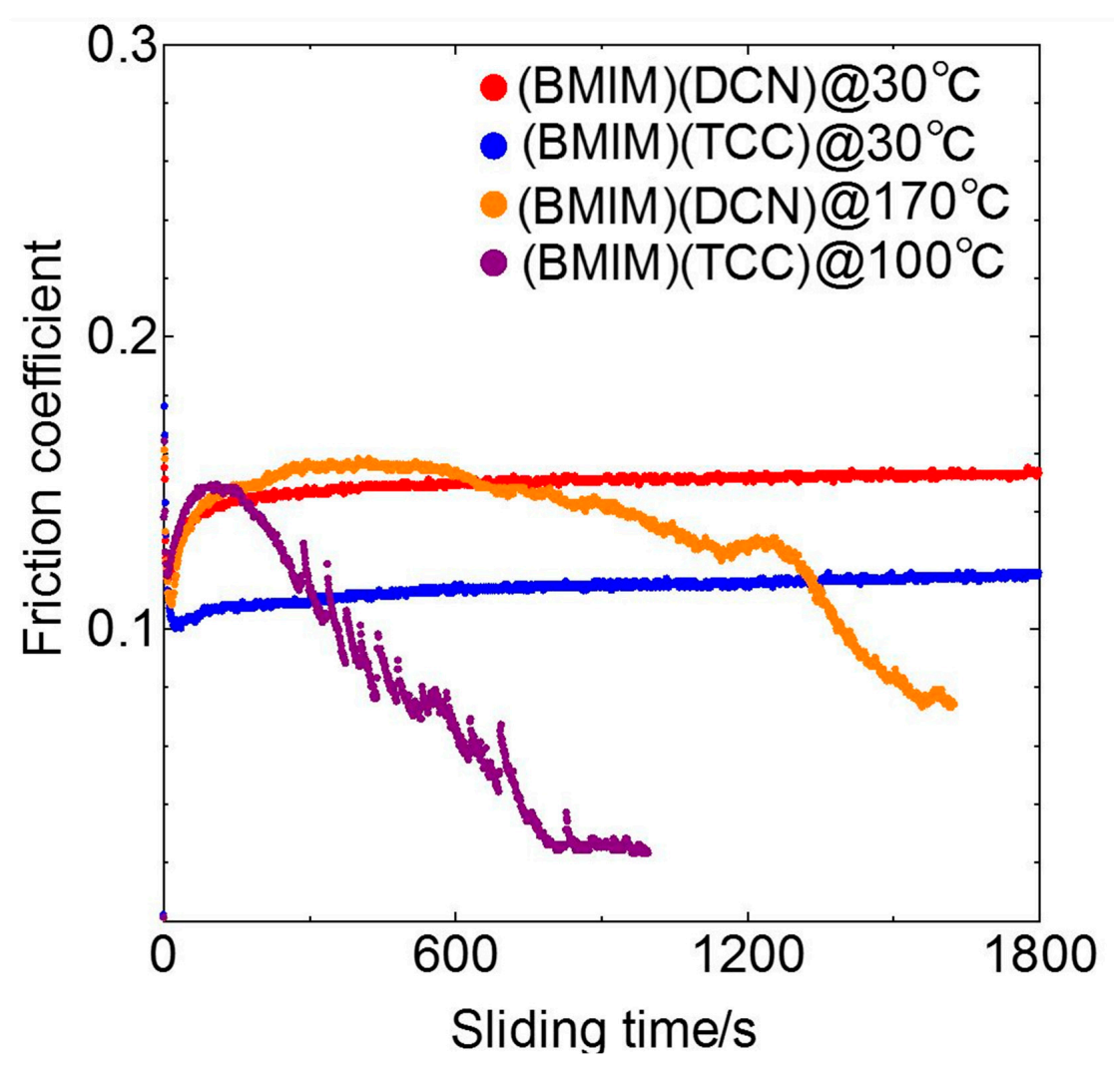

Figure 2. Frictional behavior of (BMIM)(DCN) and (BMIM)(TCC) at each temperature. 


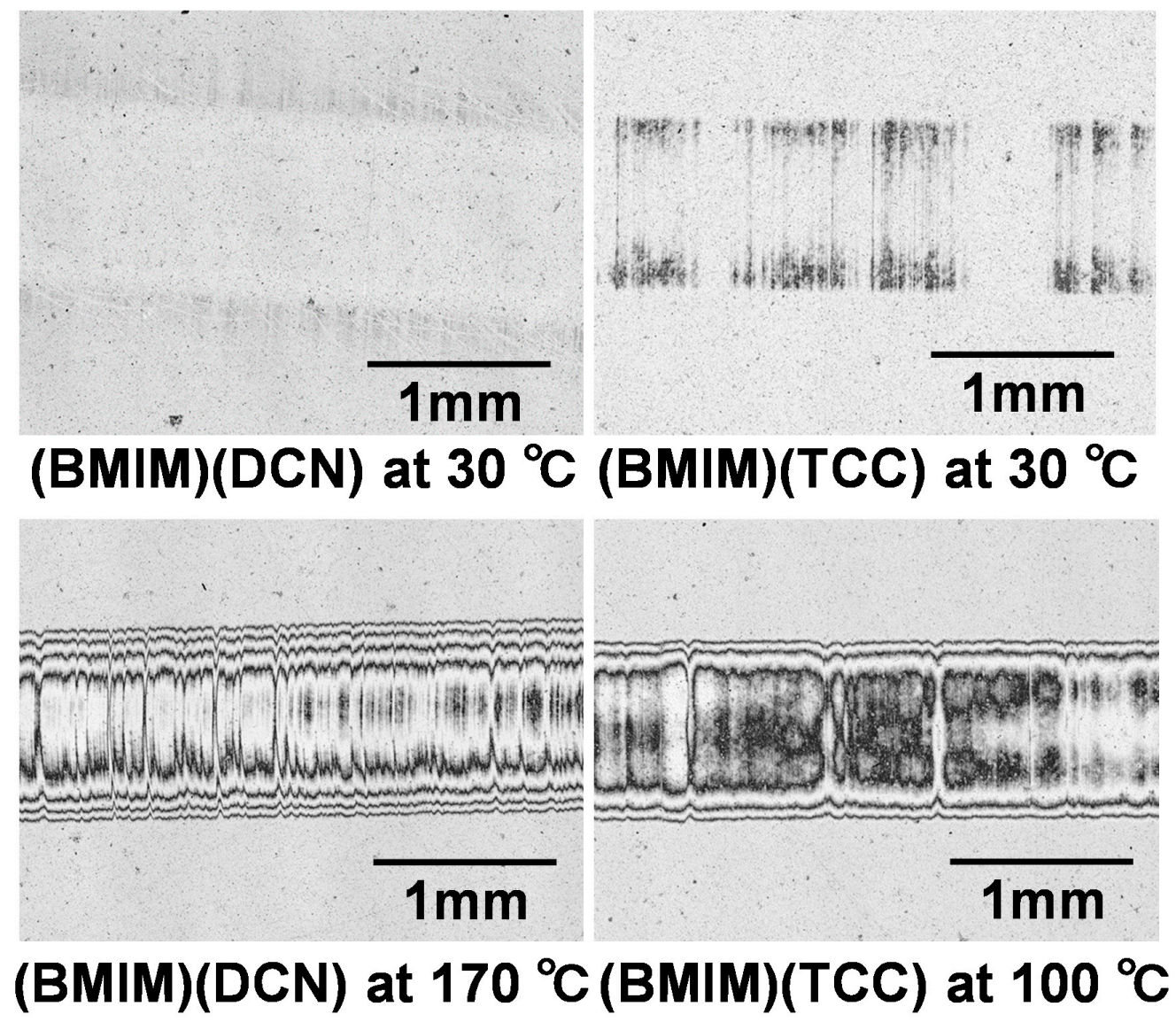

Figure 3. Images of the worn surfaces of ta-C films subjected to friction under different conditions.

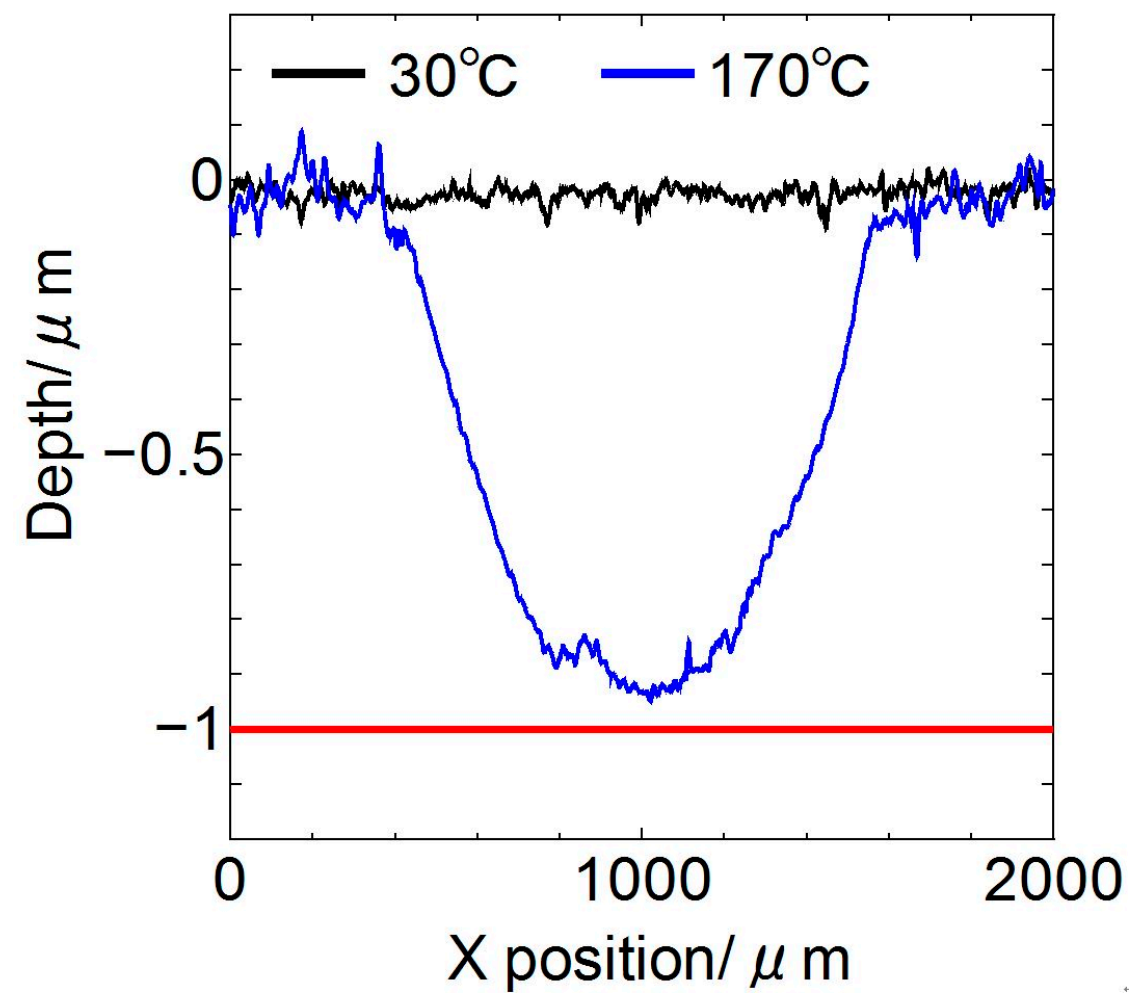

Figure 4. Surface profile of (BMIM)(DCN). 


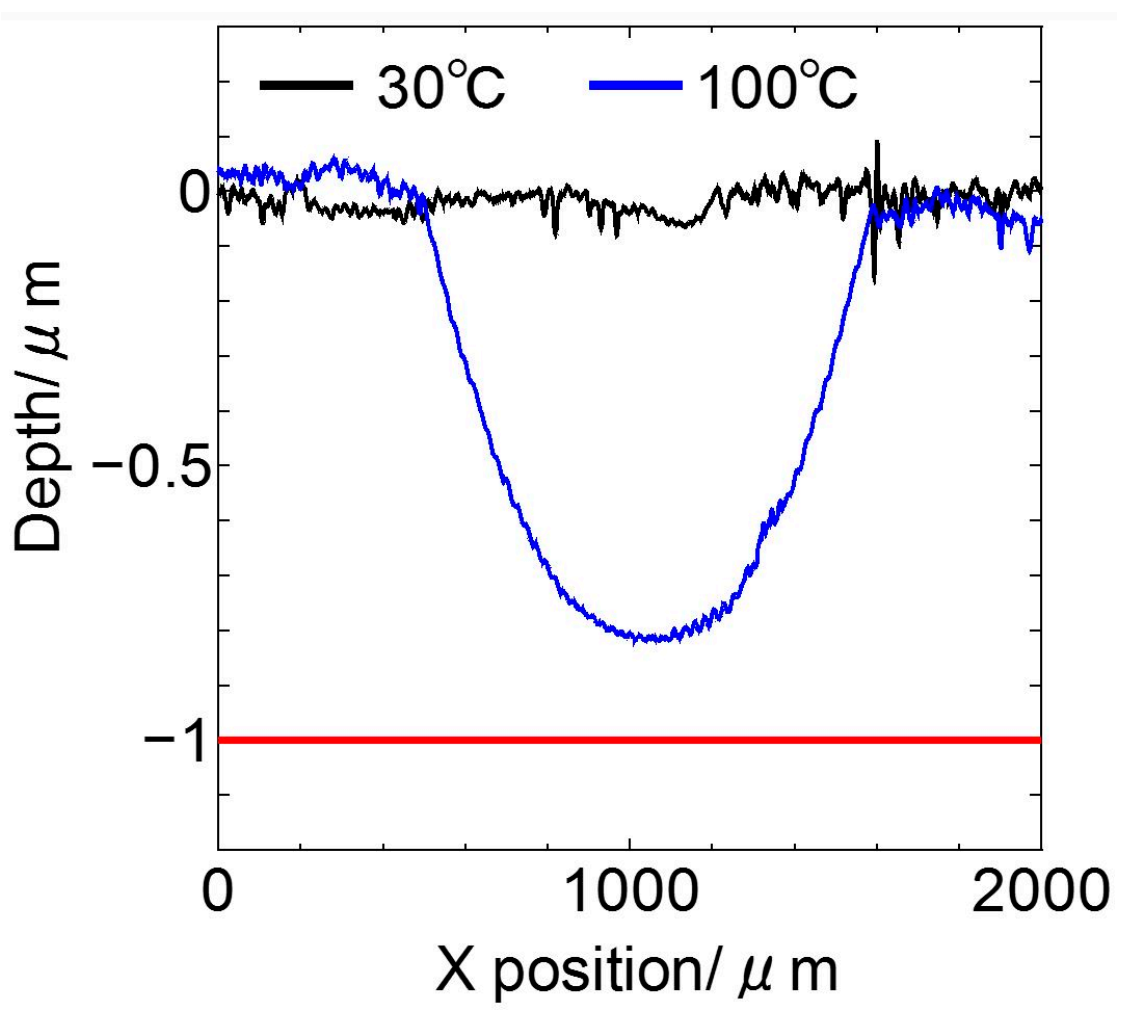

Figure 5. Surface profile of (BMIM)(TCC).

\subsection{Raman Spectroscopy}

Raman spectroscopy was performed to investigate the structural changes in the ta-C film. Figure 6 shows the Raman spectra of ta-C films after each sliding test when lubricated with (BMIM)(DCN) or (BMIM)(TCC). Figure 7 shows the $I_{\mathrm{D}} / I_{\mathrm{G}}$ ratio of the ta-C films. The interior and exterior parts of the wear track of the ta-C films were analyzed. At $30{ }^{\circ} \mathrm{C}$, no major difference was observed between the interior and exterior parts of the wear track. The graphitization proceeded on the worn surface at the temperature corresponding to the low friction coefficient. It is possible that the graphitization of the ta-C film was responsible for the reduced friction.

\subsection{MALDI-TOF/MS Results}

The surface information about the worn surface of the disks was obtained using MALDI-TOF/MS (autoflex speed, Bruker, Billerica, MA, USA) to determine the material that caused the reduction in friction. Selected cations and anions for the investigation are as follows: $($ EMIM) cation $=111,($ BMIM) cation $=139,(\mathrm{DCN})$ anion $=66$, and $($ TCC $)$ anion $=90$. In addition, no other matrix was used in this surface analysis because ionic liquids themselves are widely used as a matrix [37]. In other words, if the ions derived from the ionic liquids adsorb to the worn surface, the mass spectra and mapping images can be obtained. From the area where the ions of the ionic liquid are not adsorbed to the surface, no data should be obtained [37]. Figure 8 shows the mapping images of the disk specimens obtained by MALDI-TOF/MS. Few cations and anions were detected at $30^{\circ} \mathrm{C}$. However, anions were adsorbed on the worn surface at the temperature corresponding to the low friction coefficient. Further, the cation content was small compared to that of the anion. 

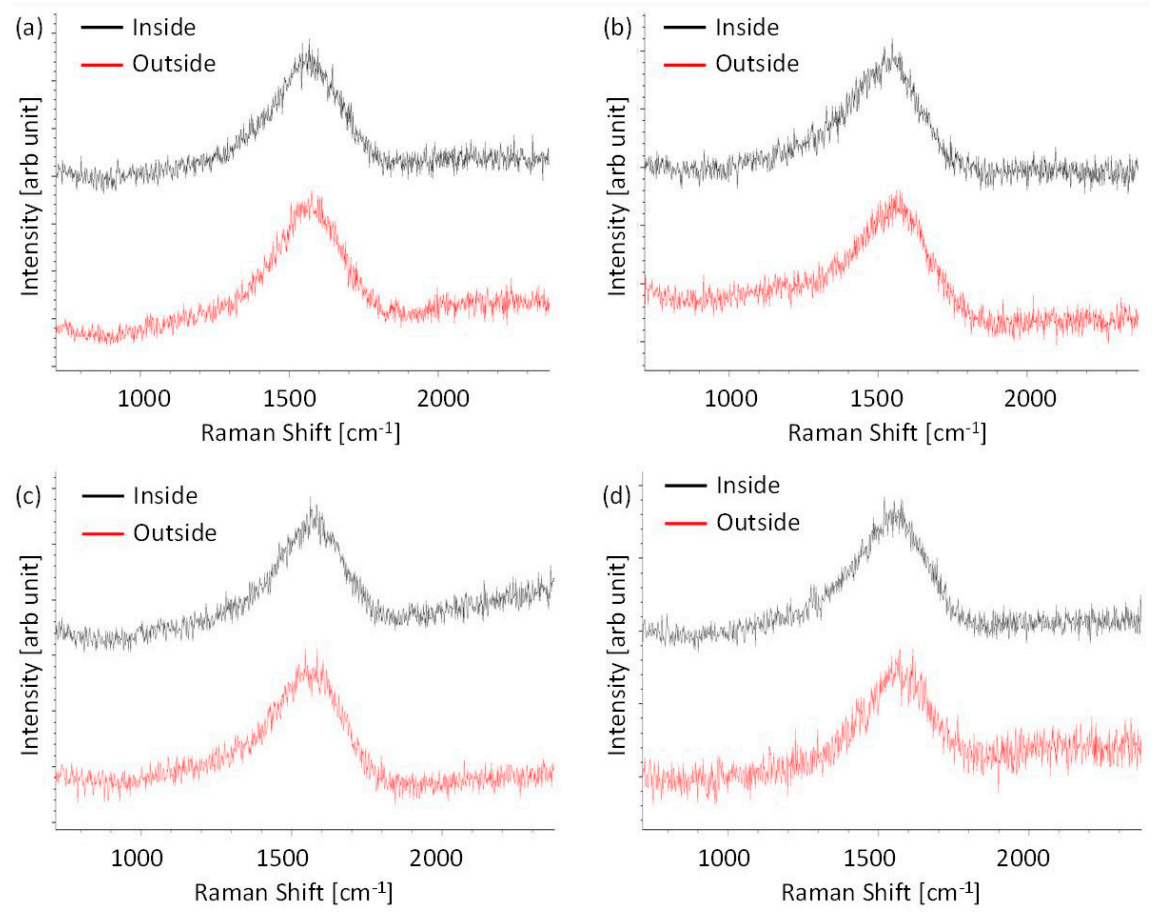

Figure 6. Results of the Raman spectroscopic analyses. (a) (BMIM)(DCN) $30^{\circ} \mathrm{C}$, (b) (BMIM)(DCN) $170{ }^{\circ} \mathrm{C}$, (c) (BMIM)(TCC) $30^{\circ} \mathrm{C}$, and (d) (BMIM)(TCC) $100{ }^{\circ} \mathrm{C}$.

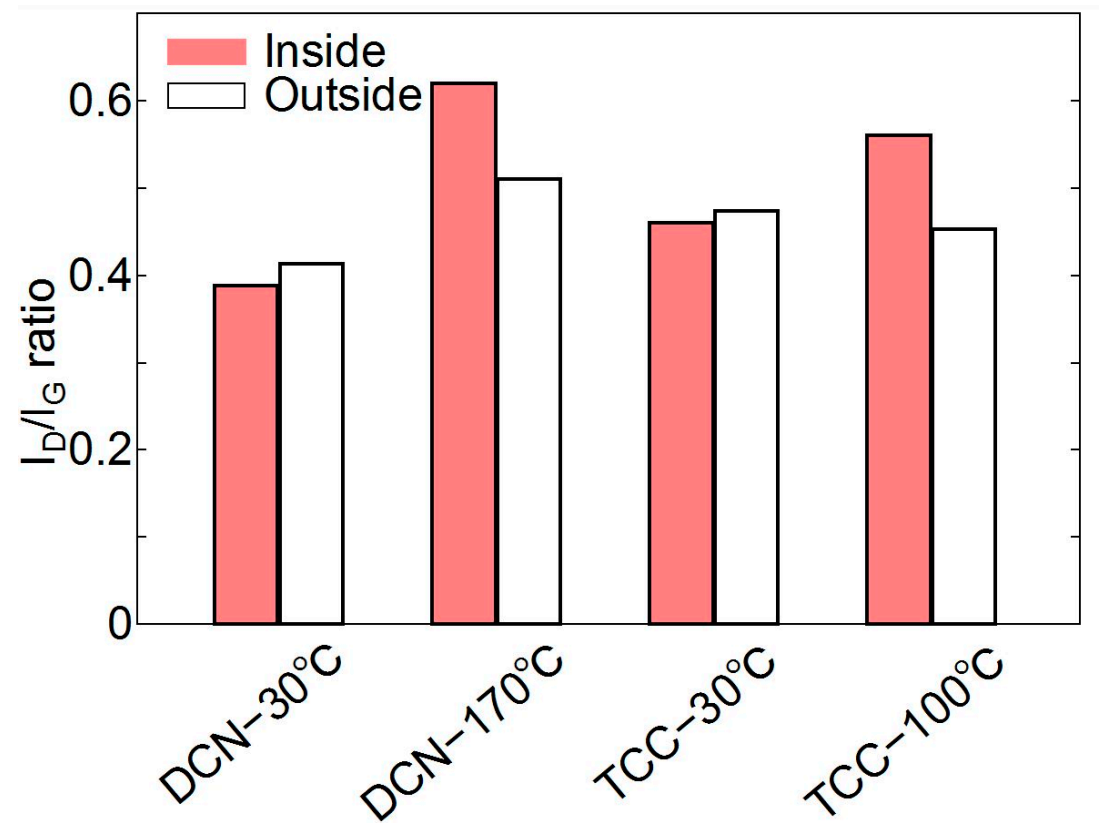

Figure 7. $I_{\mathrm{D}} / I_{\mathrm{G}}$ ratio of $(\mathrm{BMIM})(\mathrm{DCN})$ and $(\mathrm{BMIM})(\mathrm{TCC})$. 


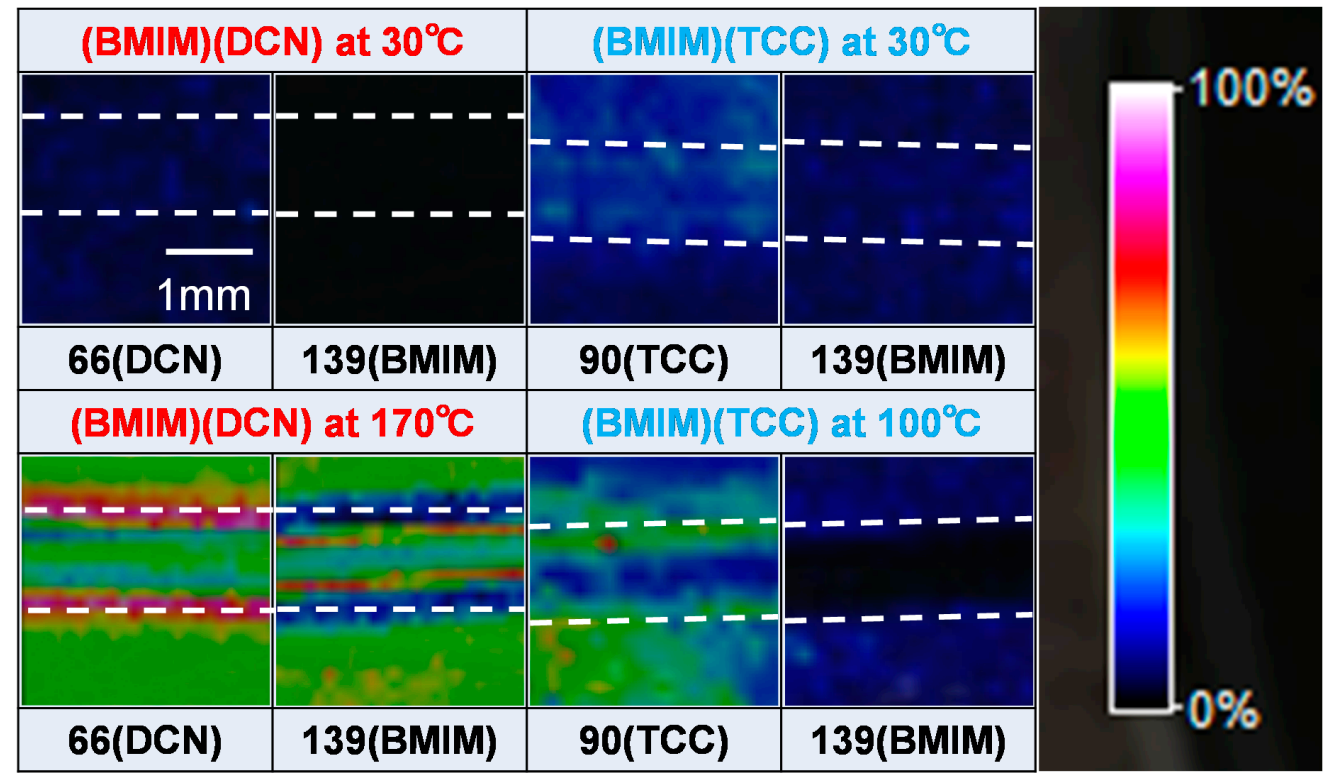

Figure 8. Mapping images of the ta-C film obtained using matrix-assisted laser desorption/ionization time-of-flight mass spectrometry (MALDI-TOF/MS).

\subsection{Thermogravimetric Analysis}

The ambient temperature affected the reaction of anions with the surface, whereas the cations did not strongly interact with the surface, as determined by MALDI-TOF/MS analysis. The interaction force between cations and anions in the ionic liquid is presumably an important factor. The stability of the ionic liquids was analyzed by TGA to investigate the ionic interaction as well. Figure 9 shows the TGA results. The temperatures corresponding to a weight loss of $\sim 5 \%$ are $300{ }^{\circ} \mathrm{C}$ for $(\mathrm{BMIM})(\mathrm{DCN})$ and $344^{\circ} \mathrm{C}$ for (BMIM)(TCC). This result seems to contradict the results of the sliding test at elevated temperatures.

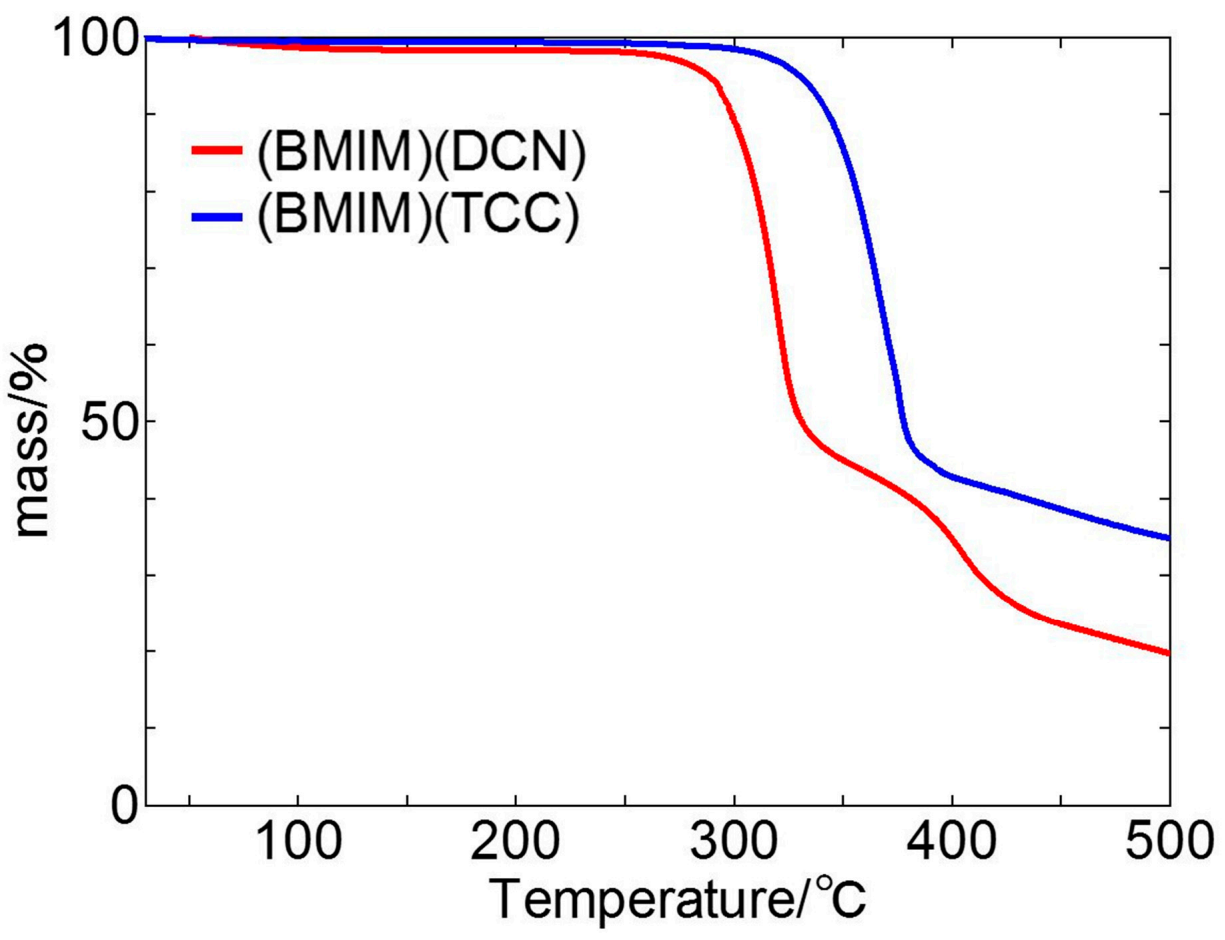

Figure 9. Thermal stability of (BMIM)(DCN) and (BMIM)(TCC). 


\section{Discussion}

In this study, the reduction in friction between steel disks lubricated with (BMIM)(DCN) and (BMIM)(TCC) was confirmed at $90^{\circ} \mathrm{C}$ and $170{ }^{\circ} \mathrm{C}$, respectively. With regard to the friction reduction mechanism of DLC, graphitization of DLC at the friction interface has been pointed out as the cause [31-36]. The results of Raman spectroscopy indicated that the graphitization of the ta-C film progressed on the worn surface at the temperature corresponding to the low friction coefficient, which affected the friction behavior. Graphitization was likely caused by the combination of ambient temperature and friction heat. However, the temperature at which the friction was reduced was different for the two cyano-based ionic liquids studied, and another factor influencing the reduction in friction can be predicted. As another possible factor responsible for the reduction in friction, the adsorption of ionic liquids on the friction surfaces was considered. MALDI-TOF/MS analyses indicated that the anions from the ionic liquid adsorbed on the worn surface at the temperature corresponding to the low friction coefficient. The presence of anions on the worn surface and the reduction in friction due to the adsorbed anions have often been reported $[19,20,32,37,38]$. It has been reported that the ta-C film surface is reactive due to the presence of dangling bonds and reacts with the lubricants [31]. Thus, it is presumed that anions are adsorbed onto the dangling bonds of the ta-C film through covalent bonding, and that the adsorption of anions dominates the friction behavior. Further, as only anions are adsorbed on the worn surface at the temperature of low friction, we speculate that the decomposition temperature of the ionic liquids is an important factor determining the friction characteristics. However, the relationship between the ion interaction and lubricating property could not be obtained from the TGA results. Therefore, we believe that the ionic liquids underwent tribo-decomposition on the worn surface at $30^{\circ} \mathrm{C}$. The anion adsorption is likely to require a high ambient temperature. Thus, both ionic liquids showed low friction at the temperature corresponding to the low friction coefficient. Moreover, the (TCC) anion more easily reacted with the ta-C film than the (DCN) anion. The worn surface likely became brittle as a result in the latter case, leading to accelerated wear.

\section{Conclusions}

The lubricating properties of two cyano-based ionic liquids against the ta-C film were investigated using a reciprocating sliding tester. In addition, the lubricating mechanism was investigated using MALDI-TOF/MS, TGA, and Raman spectroscopy.

The main findings are as follows:

- The lubricating property of each cyano-based ionic liquid against the ta-C film was influenced by the anion structure and ambient temperature. (BMIM)(TCC) exhibited exceedingly low friction at $170^{\circ} \mathrm{C}$.

- Raman results indicated the occurrence of the graphitization of the ta-C films lubricated with (BMIM)(DCN) and (BMIM)(TCC) at the temperature corresponding to the low friction coefficient, which might have affected the friction behavior.

- MALDI-TOF/MS analyses indicated that anions were adsorbed on the worn surface at the temperature corresponding to the low friction coefficient. The cation content on the worn surface was small compared to the anion content. Therefore, it is speculated that the adsorption of anions also affects the friction behavior.

- We found a contrary trend to that of the sliding test at elevated temperatures with TGA. The ionic liquids might have experienced tribo-decomposition on the worn surface at $30^{\circ} \mathrm{C}$. Anion adsorption requires a high ambient temperature.

Author Contributions: S.K. designed the experiments and wrote the initial draft of the manuscript. S.K. and H.O. performed the experiments. H.O., S.W., C.T., R.T., S.S., and M.M. designed the experiments, contributed to data collection and interpretation, and critically reviewed the manuscript. All authors approved the final version of the manuscript and agree to be accountable for all aspects of the work in ensuring that questions related to the accuracy or integrity of any part of the work are appropriately investigated and resolved. 
Funding: This research was funded by JSPS fellow grant, grant number 19K14862.

Acknowledgments: This research was supported by a JSPS fellow grant (No. 19K14862). We would like to thank Editage (www.editage.com) for English language editing.

Conflicts of Interest: The authors declare no conflict of interest.

\section{References}

1. Wilkes, J.S. A short history of ionic liquids-From molten salts to neoteric solvents. Green Chem. 2002, 4, 73-80. [CrossRef]

2. Rogers, R.D.; Seddon, K.R. Ionic liquids-Solvents of the future? Science 2003, 302, 792-793. [CrossRef] [PubMed]

3. Seddon, K.R. A taste of the future. Nat. Mater. 2003, 2, 363-365. [CrossRef] [PubMed]

4. Li, H.; Endres, F.; Atkin, R. Effect of alkyl chain length and anion species on the interfacial nanostructure of ionic liquids at the Au (111)-ionic liquid interface as a function of potential. Phys. Chem. Chem. Phys. 2013, 15, 14624-14633. [CrossRef] [PubMed]

5. Kamimura, H.; Kubo, T.; Minami, I.; Mori, S. Effect and mechanism of additives for ionic liquids as new lubricants. Tribol. Int. 2007, 40, 620-625. [CrossRef]

6. Gebbie, A.M.; Smith, M.A.; Dobbs, A.H.; Lee, A.A.; Warr, G.G.; Banquy, X.; Valtiner, M.; Rutland, W.M.; Israelachivili, N.J.; Perkin, S.; et al. Long range electrostatic forces in ionic liquids. Chem. Commun. 2017, 53, 1214-1224. [CrossRef]

7. Motobayashi, K.; Nishi, N.; Inoue, Y.; Minami, K.; Sakka, T.; Osawa, M. Potential-induced restructuring dynamics of ionic liquids on a gold electrode: Steric effect of constituent ions studied by surface-enhanced infrared absorption spectroscopy. J. Electro. Chem. 2017, 800, 126-133. [CrossRef]

8. Suzuki, A.; Shinka, Y.; Masuko, M. Tribological characteristics of imidazolium-based room temperature ionic liquids under high vacuum. Tribol. Lett. 2007, 27, 307-313. [CrossRef]

9. Kondo, H.; Seto, J.; Ozawa, K.; Haga, S. Novel lubricants for magnetic thin film media. J. Magn. Soc. J. 1989, 13, 213-218. [CrossRef]

10. Kondo, H.; Seki, A.; Watanabe, H.; Seto, J. Frictional properties of novel lubricants for magnetic thin film media. IEEE Trans. Magn. 1990, 26, 2691-2693. [CrossRef]

11. Kondo, H.; Seki, A.; Kita, A. Comparison of an amide and amine salt as friction modifiers for a magnetic thin film medium. Tribol. Trans. 1994, 37, 88-104.

12. Wamser, C.A. Hydrolysis of fluoboric acid in aqueous solution. J. Am. Chem. Soc. 1948, 70, 1209-1215. [CrossRef]

13. Swatloski, R.P.; Holbrey, J.D.; Rogers, R.D. Ionic liquids are not always green: Hydrolysis of 1-butyl-3-methylimidazolium hexafluorophosphate. Green Chem. 2003, 5, 361-363. [CrossRef]

14. Arias-Pardilla, J.; Espinosa, T.; Bermudez, M.D. Electrochemistry in Ionic Liquids; Springer: Berlin/Heidelberg, Germany, 2015; pp. 533-561.

15. Kondo, Y.; Yagi, S.; Koyama, T.; Tsuboi, R.; Sasaki, S. Lubricity and corrosiveness of ionic liquids for steel-on-steel sliding contacts. Inst. Mech. Eng. J. Eng. Tribol. 2012, 226, 991-1006. [CrossRef]

16. Kawada, S.; Watanabe, S.; Tadokoro, C.; Sasaki, S. Effects of alkyl chaing length of sulfate and phosphate anion-based ionic liquids on Tribochemical reactions. Tribol. Lett. 2018, 66, 8. [CrossRef]

17. Kondo, Y.; Koyama, T.; Tsuboi, R.; Nakano, M.; Miyake, K.; Sasaki, S. Tribological performance of halogen-free ionic liquids as lubricants of hard coatings and ceramics. Tribol. Lett. 2013, 51, 243-249. [CrossRef]

18. Minami, I.; Inada, T.; Okada, Y. Tribological properties of halogen-free ionic liquids. Inst. Mech. Eng. J. Eng. Tribol. 2012, 226, 891-902. [CrossRef]

19. Kawada, S.; Watanabe, S.; Tadokoro, C.; Tsuboi, R.; Sasaki, S. Lubricating mechanism of cyano-based ionic liquids on nascent steel surface. Tribol. Int. 2018, 119, 474-480. [CrossRef]

20. Kawada, S.; Watanabe, S.; Sasaki, S.; Miyatake, M. Evaluation of friction behavior and surface interactions of cyano-based ionic liquids under different sliding contacts and high vacuum condition. Lubricatns 2018, 6, 69. [CrossRef]

21. Shah, F.U.; Glavatskih, S.; Antzutkin, N.O. Boron in tribology: From borates to ionic liquids. Tribol. Lett. 2013, 51, 281-301. [CrossRef] 
22. Zhou, Y.; Qu, J. Ionic liquids as lubricant additives: A review. Appl. Mater. Interfaces. 2017, 9, 3209-3222. [CrossRef] [PubMed]

23. Jiang, C.; Wang, Y.; Su, H.; Li, W.; Wang, Z. Synthesis and evaluation of a protic ionic liquid as a multifunctional lubricant additive. Friction 2019, 1-9. [CrossRef]

24. Avilés, M.D.; Pamies, R.; Sanes, J.; Carrión, F.J.; Bermúdez, M.D. Fatty acid-derived ionic liquid lubricants. Protic ionic liquid crystals as protic ionic liquid additives. Coatings 2019, 9, 710. [CrossRef]

25. Guo, H.; Adukure, A.R.; Iglesias, P. Effect of ionicity of three protic ionic liquids as neat lubricants and lubricant additives to a biolubricant. Coatings 2019, 9, 713. [CrossRef]

26. Tadokoro, C.; Sato, K.; Nagamine, T.; Nakano, K.; Sasaki, S.; Sato, T.; Sakakibara, K.; Tsujii, Y. Concentrated polymer brush as reciprocating sear material for low leakage and low friction. Tribol. Tans. 2019. [CrossRef]

27. Tujii, Y.; Nomura, A.; Okayasu, K.; Gao, W.; Ohno, K.; Fukuda, T. AFM studies on microtribology of concentrated polymer brushes in solvents. J. Phys. Conf. Ser. 2009, 184, 012031.

28. Sato, K.; Okubo, H.; Hirata, Y.; Tadokoro, C.; Nakano, K.; Tsujii, Y.; Sasaki, S. Macroscopic tribological properties of thick concentrated polymer brush on rough steel under lubrication with ionic liquid. J. Tribologi. 2019, 20, 97-113.

29. Bouabibsa, I.; Lamri, S.; Sanchette, F. Structure, mechanical and tribological properties of Me-doped diamond-like carbon $(\mathrm{DLC})(\mathrm{Me}=\mathrm{Al}$, $\mathrm{Ti}$, or $\mathrm{Nb})$ hydrogenated amorphous carbon coatings. Coatings 2018, 8, 370. [CrossRef]

30. Aijaz, A.; Ferreira, F.; Oliveira, J.; Kubart, T. Mechanical properties of hydrogen free diamond-like carbon thin films deposited by high power impulse magnetron sputtering with Ne. Coatings 2018, 8, 385. [CrossRef]

31. Okubo, H.; Kawada, S.; Watanabe, S.; Sasaki, S. Tribological performance of halogen-free ionic liquids in steel-steel and DLC-DLC contacts. Tribol. Trans. 2018, 61, 71-79. [CrossRef]

32. Kawada, S.; Watanabe, S.; Tsuboi, R.; Sasaki, S.; Prakash, B. Lubrication mechanism of halogen-free ionic liquids. Tribol. Online 2017, 12, 155-161. [CrossRef]

33. Kawada, S.; Sato, K.; Watanabe, S.; Sasaki, S. Lubricating property of cyano-based ionic liquids against hard materials. J. Mech. Sci. Tech. 2017, 31, 5745-5750. [CrossRef]

34. Ogwu, A.A.; Lamberton, R.W.; Morley, S.; Maguire, P.; McLaughlin, J. Characterization of thermally annealed diamond like carbon (DLC) and silicon modified DLC films by Raman spectroscopy. Physica B Condensed Matter 1999, 269, 335-344. [CrossRef]

35. Vengudusamy, B.; Green, J.H.; Lamb, G.D.; Spikes, H.A. Tribological properties of tribofilms formed from ZDDP in DLC/DLC and DLC/steel contacts. Tribol. Int. 2011, 44, 165-174. [CrossRef]

36. Liu, Y.; Erdemir, A.; Meletis, E.I. An investigation of the relationship graphitization and frictional behaviour of DLC coatings. Surf. Coat. Tech. 1996, 86-87, 564-568. [CrossRef]

37. Christoph, G.; Ernst, P.; Nicole, D.; Gunter, A. Imaging of a Tribolayer Formed from Ionic Liquids by Laser Desorption/Ionization-Reflectron Time-of-Flight Mass Spectrometry. Anal. Chem. 2012, 84, 10708-10714.

38. Liu, X.Q.; Zhou, F.; Liang, Y.; Liu, W. Tribological performance of phosphonium based ionic liquids for an aluminum-on-steel system and opinions on lubrication mechanism. WEAR 2006, 261, 1174-1179. [CrossRef]

(C) 2020 by the authors. Licensee MDPI, Basel, Switzerland. This article is an open access article distributed under the terms and conditions of the Creative Commons Attribution (CC BY) license (http://creativecommons.org/licenses/by/4.0/). 